of these coenzymes and of the manner in which they participate in metabolism. On the medical side, the effects of vitamin deficiency are well documented and the nutritional needs of man and other organisms have been defined. And yet the integration of these two aspects of knowledge of the vitamins is still poor. The answers to such questions as which enzymes are primarily affected in deficicncy of a given vitamin, why one enzyme should be more severely affected than others for which the vitamin also provides the coenzyme, and why diminished activity of that enzyme should result in the observed signs of deficiency, are at best incomplete and at worst pure speculation.

The link betwcen coenzyme funetion and the effects of deficiency is perhaps better understood in the case of folic acid than for any other vitamin. There is substantial evidence favouring the view that thymidylate synthetase is the enzyme principally affected in folic acid doficiency, and that the conscquent lack of thymidylate in turn affects nucleic acid synthesis in rapidly proliferating tissues such as bone marrow and gut mucosa. But this hypothesis cannot yet bo said to be fully proved, and further problems, for examplc, why thymidylate synthetase is affected rather than other folic acid-requiring enzymes and whether these other enzymes also influence the manifestations of folic acid deficiency, have scarcoly been considered.

These points are admirably illustrated in this monograph. The book begins with a survey of the oceurrence of all classes of pteridines, and then discusses aspects of their chemistry relevant to the understanding of their biochemical properties. The next section of the book examines the biosynthesis of folic acid and pterjdine coenzymes. Each of the metabolic reactions in which these coenzymes take part is then considered in detail. The final section is concerned with nutritional, physiological and pharmacological aspects, and contains chapters on absorption and distribution, on folic acid deficiency, on the relationships between folic acid and cobalamin, and on folic acid analogues. Although much the greatest amount of information concerns folic acid and its coenzyme forms, the attention given to non-folic acid pteridines is particularly valuable.

A very large amount of work is reviewed in a clear and integrated exposition and the extensive bibliography is a feature of the book. But the true value of the monograph lies in the author's critical approach to his material. He assesses the validity of experimental work and of the con. clusions drawn from it, and points out areas where further investigation is needed in order to reach a full understanding.

The book is excellently produced and almost entirely free from misprints. Its only drawback seems to be its price which, one fears, may prevent the wide distribution which this illuminating account of a complex arca of biochemistry deserves.

KENNFTH M. JONES

\section{RIBOSOME STRUCTURE}

\section{The Ribosome}

By A. S. Spirin and L. P. Gavrilova. (Molecular Biology, Biochemistry and Biophysies, Vol. 4.) Pp. $\mathrm{x}+161$. (Springer-Verlag: Berlin and New York, 1969.) 54 DM; $\$ 14.90$.

Risosomes are the black boxes of molecular biology. We know what goes in and what comes out, but we have little detailed knowledge of what goes on inside. Biochemists have been able to proceed without waiting for this lsnowledge, just as electronic engineers can use integrated circuits without needing to know exactly what they contain; nevertheless, to some enthusiasts the detailed structure remains a very challenging problem.

Ribosome structure has been investigated by many techniques, some of which have much in common with those used by a primitive tribesman presented with his first watch. The object has been measured, weighed, and tosted for food value; it has been smashed to smithereens and the debris searched for meaningful fragments; the better-equipped investigators have carefully dismembered it and tried to put it together again. Some have actually triumphed in getting the reassembled timepiece to tick. It is frustrating, therefore, that at the end of all this we remain almost totally ignorant of the function of any of the component parts.

This book is an attempt to summarize current knowledge and to bridge the gaps with informed speculation. It starts with a survey of structural information, revealing only too clearly how little we know, and proceeds to a much more satisfying account of the function of ribosomes in protein synthesis. Although it is by now out of date (there are only a handful of references dated later than 1967) the biochemical information is sufficiently complete to define the essential steps in polypoptide formation and to indicate which of the two ribosomal subparticles is implicated in each.

Now that some details of the initiation process are understood, many of the somewhat puzzling early observations on cell-frec systems fall into place. It is, for instance, now clear that early experiments with synthetic homopolynucleotide messengers were only successful because the ionic environment was such as to distort the ribosomes: they failed to discriminate against messenger molecules lacking an initiator codon. The authors use this and other evidence to support the general hypothesis that a ribosome opens and shuts as it moves along the messenger RNA, like a macromolecular molluse. The book ends with a useful appendix on those antibiotics that are believed to interact with ribosomes.

The general reader may find the book heavy going. It is somewhat repetitious and rcads as though translated into English by a computer: it really should have been more thoroughly checked for infelicities of syntax before being launched into the English-speaking world. It is, however, a very useful summary and source of references for anybody interested in the details of ribosomo structure and function.

M. SPENCER

\section{MEMBRANE BIOPHYSICS}

\section{Laboratory Techniques in Membrane Biophysics}

An Introductory Course. Edited by $H$. Passow and R. Stampfli. Pp. viii +201 . (Springer-Verlag: Berlin and New York, 1969.) 34 DM; $\$ 9.40$.

The experimental techniques described in this book are largely concerned with pormeability characteristics of cell membranes or membrane systems. They have been developed chiefly by biophysical physiologists and in general would seem to require the kind of equipment that might be available in physiology laboratories together with ready access to radioactive counting facilities. Most of the experiments also involve some specialized items of equipment which would restrict them to the "circustype" laboratory teaching arrangement. Furthermore, the time spans of most of the experiments are such as to make them unsuitable for strictly limited practical sessions. Consequently, as the editors point out, these techniques in membrane biophysics are most appropriate for training courses or for postgraduate degree courses, and for these purposes the book provides an excellent coverage of both practical and theoretical background relating to techniques which have proved to be most valuable in the study of membrane permeability.

Experiments which exploit the practical advantages of erythrocytes and nerve fibres for this purpose are most numerous, but techniques for studying permeability phenomena in ycast and bacteria and in single plant cells as well as in the more complex multicellular systems of 